\title{
Quality of Life Assessment of Children with Early Childhood Caries in a Brazilian City
}

\author{
Gisele Alcântara de Carvalho', Natália de Almeida Assis Gramoza', Lídia Audrey Rocha Valadas²,*, Edilson Martins Rodrigues Neto², \\ Fernanda Matias de Carvalho ${ }^{2}$, Fernanda Leal Dantas Sales Pimentel ${ }^{3}$, Patrícia Leal Dantas Lobo ${ }^{1,2}$ \\ 'Dentistry School, Federal University of Ceara- Campus Sobral, Sobral-CE, BRAZIL. \\ 2Dentistry and Nursing School, Federal University of Ceara, Fortaleza-CE-BRAZIL. \\ ${ }^{3}$ State University of Ceara, Fortaleza-CE, BRAZIL.
}

\begin{abstract}
Objectives: The aim of the research was to investigate the impact of ECC on children's quality of life and find out how it affects their routine, through a questionnaire applied to parents. Methods: For this assessment, the Impact Scale on Oral Health in Early Childhood (ECOIHS) have been used. The sample consisted of 150 children aged 2 to 5 years enrolled in daycare centers and public schools in the municipality of Massapê-CE-Brazil. The questionnaire was answered by parents and guardians of children diagnosed with ECC. The analysis of the questionnaire was performed using SPSS software version 17.0 and R statistics 3.2. Results: In the results, with regard to toothache and difficulty in eating and drinking, a prevalence of $85.48 \%$ was found with a statistical significance of $5 \%$. $40.7 \%$ of family members considered themselves guilty at some level of intensity by ECC in children. Correlating family income with the financial impact of a dental problem and / or treatment, a prevalence of $96.35 \%$ was
\end{abstract}

observed with a 95\% confidence interval, demonstrating that the lower the family income, the greater the financial impact. Conclusion: ECC interferes with the child's quality of life, thus negatively affecting his routine, as well as that of his family.

Key words: Quality of life, Dental caries, Pre-school, Early childhood caries, oral hygiene.

\section{Correspondence}

Dr. Lidia Audrey Rocha Valadas,

Pharmacy Dentistry and Nursering School, Federal University of Ceara-1210 Capital Francisco Pedro Stre, 60430372, Fortaleza-CE, BRAZIL.

Email id: lidiavaladas@gmail.com

DOI: 10.5530/jyp.2021.13.55

\section{INTRODUCTION}

Early childhood caries (ECC) is a sugar-dependent disease with multifactorial factors that affects primary dentition. ECC is defined as the presence of at least one decayed tooth (lesion with or without cavitation), the absence of a tooth (due to caries) or the existence of a provisional restoration on a tooth, in a child aged between 0 and 71 months old. The beginning of the carious process is due to tooth demineralization promoted by organic acids resulting from the bacterial fermentation of food substrates, especially carbohydrates. The cariogenic microbiota is one of the factors associated with the disease and Streptococcus mutans, micro-organisms that ferment carbohydrates in the diet, are considered the main micro-organisms involved in the beginning of the carious lesion in children. ${ }^{1,2}$

The carious process when installed, if not controlled, can reach severe stages, negatively impacting the child's life, representing a public health problem. Children affected by caries may experience pain, problems in the function of speech and chewing, systemic diseases and psychological reflexes. ${ }^{3}$

Despite the efforts made by the dental community to control tooth decay, ECC continues to be of concern to researchers, especially in less developed countries. The etiology of early childhood caries has always been extensively studied, including considering new factors that influence its development, such as socio-economic, demographic and cognitive factors. ${ }^{3,4}$

With the development of cavities of caries lesions, the child may present with infection, pain, difficulty in chewing, psychological trauma and premature loss of teeth. Dental pain is the most common immediate consequence of untreated cavities. Children with dental pain have their daily activities affected, such as eating, sleeping and playing. In addition, it is known that such pain can negatively affect school performance and be a reason for missing school. ${ }^{3}$

The Impact Scale on Oral Health in Early Childhood (ECOHIS) was developed to assess the impact of oral health conditions on quality of life in relation to oral health (HRQoL) of preschool children (aged 2 to 5 years) and their families, and has already been validated in Portuguese for use in Brazilian populations. In addition, evidence in the areas of child development and psychology indicates that children under six years of age are unable to accurately remember everyday events after more than $24 \mathrm{hr}^{4}$

ECC interferes with both the child's and family's quality of life. The impact that this condition has is felt immediately or late, with a decrease in the learning capacity and absenteeism both from children at school and from parents at work. Such a disease is also capable of reflecting on the social behavior of children, who are often bullied by their peers. The treatment of ECC, in addition to requiring financial costs, is invasive and exhausting for the child, family and professional team, especially if the care takes place in emergency services. ${ }^{5}$

Thus, the objective was to assess the impact of early caries on children's quality of life, as well as to identify how the disease interferes with their routine and the relationship between oral health and the family's socioeconomic condition. 


\section{METHODOLOGY}

This is a quantitative and cross-sectional study, carried out in the city of Massapê, in the Brazilian state of Ceará. The research project was approved by the research ethics committee of the Federal University of Ceara under protocol no. 1.243.050. It is noteworthy that children who had carious lesions detected during the research, were referred to specialized care.

The study population consisted of children enrolled in public schools in the municipality, which has a total of six educational institutions, where 570 children under the age of 72 months study.

The inclusion criteria for the research were: children of both genders, enrolled in public institutions who had at least one visible caries lesion (ICDAS 1 to 6) on the clinical examination performed by the researchers, and who were in the age group of 0 to 71 months, which characterizes the ECC. Children aged 72 months or more, free of carious lesions or who did not reside in the municipality were excluded from the study. From the inclusion and exclusion criteria, a sample of 150 children was selected and the data obtained noted in individual clinical files.

The children's parents were invited to the school meeting and informed about the research, signing the Informed Consent Form (ICF) when they accepted that their children participate in the study. Data collection was performed by trained researchers. The children underwent a clinical examination, which was carried out in schools under natural light and with wooden spatulas on everyone aged 71 months or less.

After the examination, in children with caries lesions, parents or guardians were asked to answer a form containing questions related to socioeconomic aspects and the instrument Early Childhood Oral Health Impact Scale Semantic equivalence of the Brazilian version of the Early Childhood Oral Health Impact Scale (ECOHIS) that assesses the quality of life related to the oral health of preschool children and their families, already validated in Brazil. ${ }^{5}$

ECOHIS consists of 13 questions, divided into two main parts: the child impact section (first part) and the family impact section (second part). The impact on children section consists of four sub-scales: child symptoms, child function, child psychology and child self-image / social interaction. The family impact section contains two subscales: parental stress and family function. The questionnaire is recorded using a simple five-point Likert scale with responses ranging from "never" to "very often" (equivalent to a score of 0 and 5, respectively). The total score ranges from zero to 52, being calculated as a simple sum of the answers. Higher scores denote greater impact on oral health and / or poorer. The different ranges of the subscales are as follows: Impact section on children: Child symptoms - one item, range 0 to 4 points; child's function - four items, range from 0 to 16 points; child psychology - two items, range 0 to 8 points; and child self-image / social interaction - two items, impact section range 0 to 8 points. Family section: Questions related to parents' distress - two items, range 0 to 8 points; family function - two items vary from 0 to 8 points. ${ }^{5}$

After data collection, the results were analyzed using SPSS $^{\oplus}$ software version 20.0 for Windows ${ }^{\oplus}$ (Statistical Package for the Social Sciences, SPSS Inc., Chicago, Illinois, USA, 2010, www.spss.com) and the R statistics 3.2. In all cases, the level of significance was set at $0.05(5 \%)$, with $P<0.05$ being considered statistically significant.

\section{RESULTS}

Between 150 children, 56\% were male and 46\% female. For each child, a global impact score was generated, from the sum of the scores obtained in the 13 items of the questionnaire ( 0 to 5 , in each item). The values found ranged from 0 to 36 (mean $=6.82)$. Of the total, 114 had scores from 0 to 10,20 had scores from 11 to 20 and 16 had scores greater than 21 (Figure 1).

After analyzing the results, it was observed that 79 participants (55.7\%) never had a toothache episode, followed by 39 (26\%) who had occasional manifestations. These data show that caries has a painful influence on dentition (Table 1).

Table 2 shows that 88 participants (58.7\%) never had episodes of tooth sensitivity when ingesting cold or hot liquids, followed by 25 (16.7\%) who presented sensitivity rarely or occasionally. Thus, it is evident that more than a third of children with caries have already presented some episode of sensitivity.

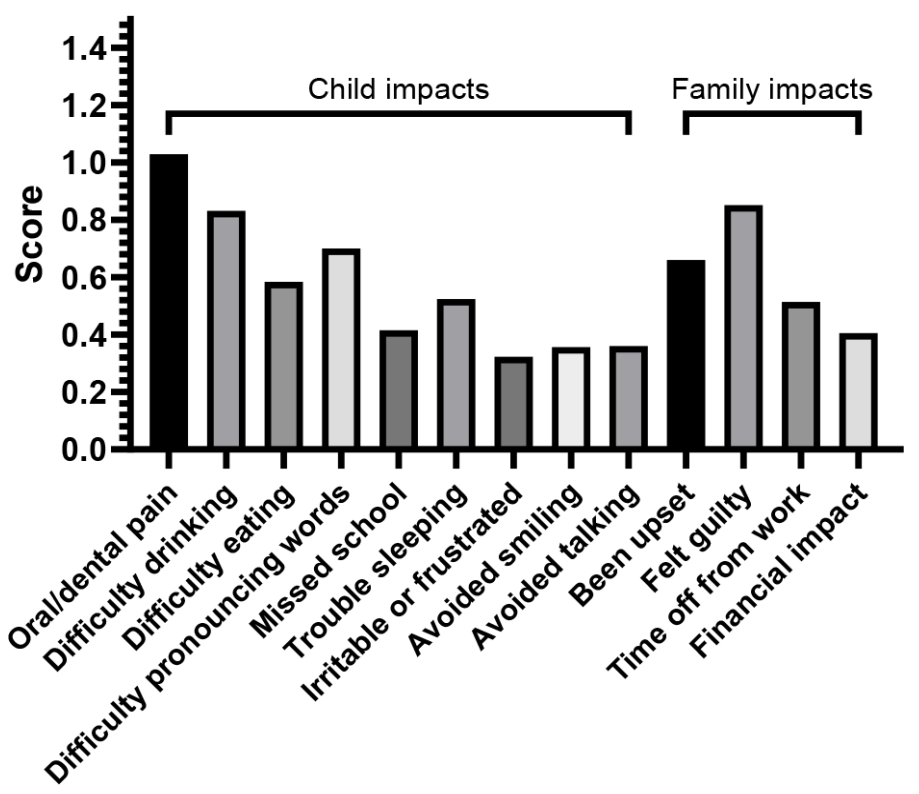

Figure 1: ECOHIS scores of children impacts and their family impacts.

Table 1: Frequency of toothache manifestation in the surveyed patients, Massapê-CE, 2019.

\begin{tabular}{ccc}
\hline Frequency of toothache & N & $\%$ \\
\hline Never & 79 & 55,7 \\
Rarely & 19 & 12,7 \\
Occasionally & 39 & 26,0 \\
Frequently & 5 & 3,3 \\
Always & 3 & 2,0 \\
Did not know & 5 & 3,3 \\
Total & 150 & 100,0 \\
\hline
\end{tabular}

Table 2: Frequency of episodes of tooth sensitivity in the intake of cold and hot fluids, Massapê-CE, 2019.

\begin{tabular}{ccc}
\hline Frequency of dental hipersensibility & N & $\%$ \\
\hline Nunca & 88 & 58.7 \\
Rarely & 25 & 16.7 \\
Occasionally & 25 & 16.7 \\
Frequently & 5 & 3.3 \\
Always & 3 & 2.0 \\
Did not know & 4 & 2.7 \\
Total & 150 & 100.0 \\
\hline
\end{tabular}


In view of episodes of difficulty in eating food caused by cavities and / or dental treatments, it was observed that $48(32.1 \%)$ already had some episode of difficulty. When applying the chi-square test, it was observed that the relationship between toothache and difficulty in eating and drinking showed a prevalence of $85.4 \%(P=0.05)$. Apparently caries and dental procedures for their treatment seem to have no significant negative impact on school life, as only 10 children (6.7\%) rarely missed school and $7.3 \%$ occasionally $(n=11)$, and only two $(1.3 \%)$ children often missed class.

The shame of smiling, due to dental problems and treatments, was reported by $16 \%$ of the participants, namely: 15 (10\%) rarely; four occasionally $(2.7 \%)$; two frequently (1.3\%); and three always (2\%). It is noticed that dental problems and treatments are not significant when related to the shame of smiling, given that $81.3 \%$ of children did not have this problem.

Regarding the culpability resulting from the treatments and dental problems of the children, $40.7 \%$ of the family members found themselves guilty at some level of intensity for the dental problems. However, $10(6.7 \%)$ rarely; 20 (13.4\%) occasionally; nine (6\%) frequently and seven $(4.7 \%)$ always.

In general treatments and dental problems did not cause significant financial impacts on the family budget, as $84.7 \%$ answered that they never had financial problems due to these treatments.

In the analysis of socioeconomic issues, such as the place where the child live, it was observed that $101(67.3 \%)$ children had a structured family composed of father and mother, $42(28 \%)$ lived with their grandparents maternal. In addition, $121(80.7 \%)$ of the families were composed of four to six members, $113(75.3 \%)$ of the households being financially supported by only one family member, $75.3 \%$. It was observed that the higher the family income, the lower the prevalence of caries in childhood, with 135 (90\%) having a monthly family income of up to two minimum wages (Graph 1). Among the interviewees, 72 (48\%) answered that they did not actively participate in the composition of the family budget, with only $14(9.3 \%)$ responsible for the family's subsistence. Regarding education, $120(80 \%)$ reported that they studied entirely in public schools and only one $(0.7 \%)$ in private schools entirely.

When applying the chi-square test correlating family income with the financial impact of a problem and / or dental treatment, a prevalence of $96.3 \%$ ( $P=0.05)$ was observed, demonstrating that the lower the family income, the greater the financial impact of the treatment or dental problem.

\section{DISCUSSION}

The assessment of HRQoL in children of preschool age involves methodological problems such as changes in the child's ability to understand at different ages and the difficulty of separating the child's perceptions from those of their parents. ${ }^{6}$ However, as the responsibility for the health of the older children is usually of the parents, knowledge of their perception of their children's oral health becomes extremely important. ${ }^{7}$ ECOHIS was developed in order to provide valid and reliable information about the HRQoL of preschool children from the parents' perception, which has been demonstrated in several studies. ${ }^{8-10}$

The items related to pain, irritation, difficulties to eat and sleep, present in the questionnaire were the most frequently reported by parents / guardians, in agreement with the findings observed in other studies. ${ }^{6,710,11}$ In the present study, there was an interrelation between toothache and difficulty in eating and drinking at a prevalence of $85.48 \%$.

Although the study did not find relevance between self-esteem and the presence of caries, because during the survey only $16 \%$ reported some frequency in the shame of smiling, studies cited by Almeida et al. ${ }^{12}$ show that oral diseases in childhood negatively affect children's self-esteem and their interest in social practices, such as their behavior at school and in the family environment, also pointing out that physical and emotional development is directly influenced by oral health conditions.

The shame of speaking for dental problems was also not very common, with only $5.3 \%$ of the answers. This low frequency of positive responses can be explained by the age group used in the study, since it is from the age of six that abstract thinking, self-concept and self-esteem begin their development. ${ }^{13}$

Regarding the impact on the family, only $11.3 \%$ reported some type of annoyance, since guilt is much more frequent, being reported by $40.7 \%$ of the interviewed parents. In previous studies, ${ }^{10,11}$ the impacts on the family that were most frequently reported were: getting bored and feeling guilty, which are related to the parents' distress. These aspects are cited, as parents feel guilty about their child's poor diet, high sucrose intake and lack of patience to monitor and insist on cleaning the children's oral cavity.

It was observed that $15.3 \%$ of children miss the classes due to toothache or to seek care, which apparently may not interfere with school performance. Some parents do not notice this interference, as the children evaluated are very young and they do not give such importance to this performance. It is important to note that children with carious lesions usually have difficulty in eating properly and, consequently, may have some developmental deficit. ${ }^{14}$

The domain of family function, which addresses the frequency with which parents missed work and had a financial impact, despite not having a high frequency of positive responses, with $84.7 \%$ of parents reporting that they never had financial problems due to treatment dentistry, also showed a negative impact on the HRQoL of the families of these children. This finding was also observed in other studies, pointing out that the presence of dental caries in the child can cause stress in the family, resulting in disturbed sleep and loss of work days for parents / guardians, who need to stay at home to care for their children, in addition to spending on access to dental care. ${ }^{15}$

Corroborating with a study by Goettems et al. ${ }^{16}$ Socioeconomic characteristics such as monthly family income were associated with a greater impact on HRQoL. Although the population is quite homogeneous, with a socio-economic profile ranging from low to very low, any financial expenditure on children's oral health affects the family's financial condition. In the present study, when financial impact and dental treatment were correlated, a prevalence of $96.35 \%$ was observed in a $95 \%$ confidence interval.

The literature shows that research that used ECOHIS to assess HRQoL of preschool children and their families is still recent. Despite presenting limitations, the results of this study can be useful, in the sense of stimulating the development of new research in this field, since the possibility of assessing the HRQoL of preschool children allows to measure how much oral diseases and disorders can affect their lives.

\section{CONCLUSION}

ECC had a negative impact on the quality of life of children and the family. The children analyzed showed a relationship between the presence of caries and difficulty drinking and eating. Regarding self-esteem, there was no significant association, which may be related to the age group investigated. The quality of life of the families also had a negative impact, especially when it relates the feeling of guilt of the parents for the children having some stage of the caries disease. In the socio-economic context, it was concluded that the lower the family's income, the greater the financial impact of this treatment. 


\section{CONFLICT OF INTEREST}

The authors declare that there is no conflict of interest.

\section{ABBREVIATIONS}

ECC: Early Childhood Caries; ECOHIS: Early Childhood Oral Health Impact Scale; HRQoL: Health-related quality of life; ICDAS: International Caries Detection and Assessment System; ICF: Informed Consent Form.

\section{REFERENCES}

1. Valadas LAR, Gurgel MF, Mororó JM, Fonseca SGDC, Fonteles CSR, de Carvalho CBM, et al. Dose-response evaluation of a copaiba-containing varnish against Streptococcus mutans in vivo. Saudi Pharm J. 2019;27(3):363-7. doi: 10.1016/j.jsps.2018.12.004, PMID 30976179

2. Pitts NB, Zero DT, Marsh PD, Ekstrand K, Weintraub JA, Ramos-Gomez F, Tagami J, Twetman S, Tsakos G, Ismail A. Dental caries. Nat Rev Dis Primers. 2017;3(1):17030. doi: 10.1038/nrdp.2017.30, PMID 28540937.

3. Lai SHF, Wong MLW, Wong HM, McGrath CPJ, Yiu CKY. Factors influencing the oral health-related quality of life among children with severe early childhood caries in Hong Kong. Int J Dent Hyg. 2019;17(4):350-8. doi: 10.1111/idh.12414, PMID 31278830

4. Gomes MC, Pinto-Sarmento TCA, Costa EMMB, Martins CC, Granville-Garcia AF Paiva SM. Impact of oral health conditions on the quality of life of preschool children and their families: a cross-sectional study. Health Qual Life Outcomes. 2014;12:55. doi: 10.1186/1477-7525-12-55, PMID 24745700.

5. Martins-Júnior PA, Ramos-Jorge J, Paiva SM, Marques LS, Ramos-Jorge ML. Validations of the Brazilian version of the Early Childhood Oral Health Impact Scale (ECOHIS). Cad Saude Publica. 2012;28(2):367-74. doi: 10.1590/s0102311×2012000200015, PMID 22331162.

6. Åkesson ML, Wärnberg Gerdin EW, Söderström U, Lindahl B, Johansson I. Health-related quality of life and prospective caries development. BMC Oral Health. 2016;16(1):15. doi: 10.1186/s12903-016-0166-3, PMID 26860617.

7. Corrêa-Faria P, Daher A, Freire MDCM, de Abreu MHNG, Bönecker M, Costa LR
Impact of untreated dental caries severity on the quality of life of preschool children and their families: a cross-sectional study. Qual Life Res. 2018:27(12):3191-8. doi: 10.1007/s11136-018-1966-5, PMID 30097914.

8. Abanto J, Paiva SM, Sheiham A, Tsakos G, Mendes FM, CordeschiT, Vidigal EA Bönecker M. Changes in preschool children's OHRQoL after treatment of denta caries: responsiveness of the B-ECOHIS. Int J Paediatr Dent. 2016;26(4):259-65. doi: 10.1111/ipd.12192, PMID 26370072.

9. Lee GH, McGrath C, Yiu CK, King NM. Translation and validation of a Chinese language version of the Early Childhood Oral Health Impact Scale (ECOHIS). Int J Paediatr Dent. 2009;19(6):399-405. doi: 10.1111/j.1365-263X.2009.01000.X, PMID 19811551

10. Scarpelli AC, Paiva SM, Viegas CM, Carvalho AC, Ferreira FM, Pordeus IA. Oral health-related quality of life among Brazilian preschool children. Community Dent Oral Epidemiol. 2013;41(4):336-44. doi: 10.1111/cdoe.12022, PMID 23253051.

11. Corrêa-Faria P, Martins-Júnior PA, Vieira-Andrade RG, Marques LS, RamosJorge ML. Factors associated with the development of early childhood caries among Brazilian preschoolers. Braz Oral Res. 2013;27(4):356-62. doi: 10.1590/ S1806-83242013005000021, PMID 23780495.

12. Almeida TF, Couto MC, Oliveira MS, Ribeiro MB, Vianna MIP. Occurrence of dental caries and associated factors in children from 24 to 60 months living in areas covered by the Family Health Program, Salvador - BA, 2008. Rev Odontol UNESP. 2010;39(6):355-62.

13. Rebok G, Riley A, Forrest C, Starfield B, Green B, Robertson J, Tambor E. Elementary school-aged children's reports of their health: a cognitive interviewing study. Qual Life Res. 2001;10(1):59-70. doi: 10.1023/a:1016693417166, PMID 11508476.

14. Araujo AR, Santos MTBR, Duarte DA. O impacto da doença cárie na qualidade de vida em crianças de 08 a 10 anos. Vol. 54(1). Casa, São Paulo: Arq Med Hospital Faculté Cienc Med Santa; 2009. p. 1-5.

15. Castilho ARFd, Mialhe FL, BarbosaTdS, Puppin-Rontani RM. Influence of family environment on children's oral health: a systematic review. Jornal de Pediatria. 2013;89(2):116-23. doi: 10.1016/j.jped.2013.03.014.

16. Goettems ML, Ardenghi TM, Romano AR, Demarco FF, Torriani DD. Influence of maternal dental anxiety on oral health-related quality of life of preschool children. Qual Life Res. 2011;20(6):951-9. doi: 10.1007/s11136-010-9816-0 PMID 21181500.

Article History: Received 18-04-2021; Revised 21-05-2021; Accepted 11-06-2021

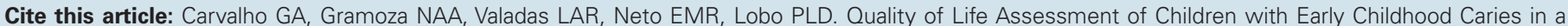
Brazilian City. J Young Pharm. 2021;13(3):270-3. 